\title{
EFEKTIVITAS PERASAN DAUN KEJI BELING (Sericocalyx crispus Linn) DALAM MENGHAMBAT PERTUMBUHAN Staphylococcus aureus
}

\author{
Dita Artanti ${ }^{1}$, Siti Fatimah ${ }^{2}$ \\ ${ }^{1) 2)}$ Prodi D3 Analis Kesehatan, FIK, Universitas Muhammadiyah Surabaya \\ dita.artanti3009@yahoo.com
}

\begin{abstract}
Tangal Submit:

30 November 2017

Tanggal Review:

18 Desember 2017

Tanggal Publish Online:

22 Desember 2017

Indonesia with the title gemah ripah loh jinawi is never separated from the wealth of its natural resources, especially on the type of flora. Indonesia is rich in the types of medicinal plants one of which is a Keji beling plant. The Keji beling plants by the community are used as anti diabetic, diuretic, antisipilis, antioxidant, antimicrobial, and laksatif. A research has been conducted to determine the effectiveness of the vermicelli leaves (Sericocalyx crispus linn) in inhibiting the growth of Staphylococcus aureus. This study was experimental laboratory consisting of 24 samples with 6 treatments with 4 replications. The concentration of the vermicelli leaves is $0 \%, 10 \%, 25 \%, 50 \%, 75 \%$, and $100 \%$. The method used in this research is dilution method. Data were analyzed by ANOVA analysis at $5 \%$ error rate $(\alpha=0,05)$. The follow-up test uses Tukey's Honest Significant Difference (Tukey's HSD) test. The results showed that the vermicelli leaves are effective in inhibiting the growth of Staphylococcus aureus. The concentration of the best Keji beling leaves that can inhibit the growth of S. aureus is at $100 \%$ concentration because only 19 colonies grow. While the minimum inhibitory power is obtained at a concentration of $75 \%$.
\end{abstract}

Keywords : : Keji beling leaves, Staphylococcus aureus

\section{PENDAHULUAN}

Staphylococcus aureus merupakan bakteri Gram positif berbentuk bulat berdiameter $0,7-1,2 \mu \mathrm{m}$, tersusun dalam kelompok-kelompok yang tidak teratur seperti buah anggur, fakultatif anaerob, tidak membentuk spora, dan tidak bergerak. Bakteri ini tumbuh pada suhu optimum $37^{\circ} \mathrm{C}$, tetapi membentuk pigmen paling baik pada suhu kamar $\left(20-25{ }^{\circ} \mathrm{C}\right)$. Koloni pada perbenihan padat berwarna abu-abu sampai kuning keemasan, berbentuk bundar, halus, menonjol, dan berkilau. Lebih dari $90 \%$ isolat klinik menghasilkan S. aureus yang mempunyai kapsul polisakarida atau selaput tipis yang berperan dalam virulensi bakteri (Jawetz et al, 2008).

Infeksi oleh $S$. aureus ditandai dengan kerusakan jaringan yang disertai abses bernanah. Beberapa penyakit infeksi yang disebabkan oleh $S$. aureus adalah bisul, jerawat, impetigo, dan infeksi luka. Infeksi yang lebih berat diantaranya pneumonia, mastitis, plebitis, meningitis, infeksi saluran kemih, osteomielitis, dan endokarditis. $S$. 
aureus juga merupakan penyebab utama infeksi nosokomial, keracunan makanan, dan sindroma syok toksik (Ryan, et al., 1994; Warsa, 1994).

Bisul atau abses setempat, seperti jerawat dan borok merupakan infeksi kulit di daerah folikel rambut, kelenjar sebasea, atau kelenjar keringat. Mula-mula terjadi nekrosis jaringan setempat, lalu terjadi koagulasi fibrin di sekitar lesi dan pembuluh getah bening, sehingga terbentuk dinding yang membatasi proses nekrosis. Infeksi dapat menyebar ke bagian tubuh lain melalui pembuluh getah bening dan pembuluh darah, sehingga terjadi peradangan pada vena, trombosis, bahkan bakterimia. Bakterimia dapat menyebabkan terjadinya endokarditis, osteomielitis akut hematogen, meningitis atau infeksi paru-paru (Warsa, 1994; Jawetz et al., 1995).

Kontaminasi langsung S. aureus pada luka terbuka (seperti luka pascabedah) atau infeksi setelah trauma (seperti osteomielitis kronis setelah fraktur terbuka) dan meningitis setelah fraktur tengkorak, merupakan penyebab infeksi nosokomial (Jawetz et al., 1995).

Keracunan makanan dapat disebabkan kontaminasi enterotoksin dari $S$. aureus. Waktu onset dari gejala keracunan biasanya cepat dan akut, tergantung pada daya tahan tubuh dan banyaknya toksin yang termakan. Jumlah toksin yang dapat menyebabkan keracunan adalah 1,0 $\mu \mathrm{g} / \mathrm{gr}$ makanan. Gejala keracunan ditandai oleh rasa mual, muntah- muntah, dan diare yang hebat tanpa disertai demam (Ryan, et al., 1994).

Pengobatan penyakit akibat infeksi $S$. aureus selama ini dapat dilakukan secara medis dan tradisional. Pengobatan secara medis menggunakan obat-obatan yang berbahan dasar kimia, seperti Amoxcillin, Kloramfenikol, Penicillin. Keseluruhan obat memiliki resistensi yang berbeda tergantuk seberapa banyaknya bakteri yang menginfeksi. Untuk itu diperlukan alternatif pengobatan tradisional yang memanfaatkan bahan alami atau biasa disebut dengan istilah back to nature. Salah satunya adalah menggunakan tanaman obat. Salah satu tanaman yang digunakan sebagai obat tradisional adalah keji beling (Sericocalyx crispus Linn). Tanaman tersebut juga digunakan sebagai antimiikroba. Daun keji beling memiliki kandungan polifenol, saponin, alkaloid, kalium dan kalsium. Selain itu juga ditemukan kumarin, flavonoid dan sterol (Mursito, 2005).

Studi literatur terkait penelitian manfaat keji beling dalam menghambat pertumbuhan $S$. aureus masih minim. Namun berdasarkan hasil penelitian Benigna (2015) menunjukkan bahwa uji daya hambat menggunakan ekstrak daun keji beling terhadap bakteri Salmonella typhi pada konsentrasi 10\%, 25\%, 50\%, 75\%, dan 100\% membentuk zona hambat dengan diameter yang berbeda. Konsentrasi 100\% memiliki zona hambat paling lebar yaitu 13 mm. Sedangkan nilai Kadar Hambat Minimum (KHM) belum bisa ditentukan. 
Dari latar belakang di atas peneliti ingin membuktikan efektivitas perasan daun keji beling (Sericocalyx crispus Linn) dalam menghambat pertumbuhan Staphylococcus aureus. Hasil penelitian daun keji beling (Sericocalyx crispus Linn) ini diharapkan dapat bermanfaat bagi pemakaian tanaman obat tradisional untuk antimikroba pada pengobatan infeksi $S$. aureus pada khususnya dan pengembangan tanaman obat pada umumnya.

\section{METODE PENELITIAN}

\section{Alat}

Alat yang digunakan dalam penelitian ini meliputi Timbangan Triple Beam Balance, Gelas arloji, cawan Petri, Beaker gelas, Erlenmeyer, pipet Pasteur, Kaki Tiga, Tabung reaksi, Autoklaf, Inkubator, Rak tabung, Mortar alu, batang pengaduk, Filler, Ose, Tabung Sentrifus, sentrifus, gelas ukur, colony counter dan pipet ukur.

\section{Bahan}

Bahan yang digunakan dalam penelitian ini meliputi daun Keji Beling (Sericocalyx crispus Linn), biakan S. aureus, akuades steril, spirtus, media Mannitol Salt Agar (MSA), media Nutrient Agar (NA), $\mathrm{NaOH} 0,1 \mathrm{~N}$, dan $\mathrm{HCl} 0,1 \mathrm{~N}$

\section{Prosedur Kerja}

\section{Pembuatan Suspensi Kuman}

\section{Staphylococcus aureus}

Tabung steril diisi dengan $\mathrm{pz} \pm 5 \mathrm{ml}$. Kemudian diambil kuman dari biakan Staphylococcus aureus murni yang sudah ditanam dimedia NAS dengan lidi kapas steril. Selanjutnya dicelupkan lidi kapas steril yang sudah ada kumannya pada tabung yang berisi pz. Lalu dibandingkan warna suspensi kuman dengan standar mc. Farland I dengan ketentuan 1) Apabila warna kurang keruh, maka ditambahkan kuman dengan lidi kapas, dan 2) Apabila terlalu keruh tambahkan pz hingga warnanya sama dengan standar mc. Farland I. Setelah didapatkan kuman yang sesuai standart Mac Farland I didapatkan hasil 1: $300.000 .000\left(3 \times 10^{8} \mathrm{CFU} / \mathrm{ml}\right)$. Suspensi kuman diencerkan hingga mendapatkan hasil 1: $1000\left(3 \times 10^{3} \mathrm{CFU} / \mathrm{ml}\right)$.

\section{Pembuatan Konsentrasi Perasan} Daun Keji Beling (Sericocalyx crispus Linn)

Daun keji beling di timbang \pm 800 gr. Kemudian daun keji beling dicuci bersih kemudian dibilas dengan aquadest steril, setelah itu ditumbuk sampai benar-benar halus. Selanjutnya daun keji beling yang telah ditumbuk tadi disaring dengan kasa berlapis yang steril. Di saring sampai benar-benar jernih. Perasan kembali disentrifus di tabung sentrifus yang steril sehingga didapatkan perasan yang benar-benar jernih. Pada perasan yang sudah jernih diambil satu mata ose secara steril, kemudian ditanam ke media Nutrien Agar Plate, dengan cara digoreskan pada permukaan media. Inkubasi selama 24 jam $37^{\circ} \mathrm{C}$. Hasil yang diamati yaitu, jika tidak terjadi pertumbuhan kuman berarti perasan keji beling tadi sudah benar-benar steril. Namun jika pada media MSA terdapat pertumbuhan kuman berarti perlu dilakukan 
proses tindalisai, yaitu 1) Perasan keji beling dipanaskan dengan waterbath pada suhu $90^{\circ} \mathrm{C}$ selam 15 menit, 2) Kemudian diletakkan di inkubator selama 24 jam pada suhu $37^{\circ} \mathrm{C}$ diulangi perlakuan tersebut sampai 4 kali, 3) perasan keji beling yang sudah melalui proses tindalisasi ditanam kembali ke media Nutrien Agar Plate dan diinkubasi selama 24 jam $37^{\circ} \mathrm{C}$.

Pembuatan konsentrasi 100\%, 75\%, $50 \%, 25 \%, 10 \%, 0 \%$ yaitu : 1) Konsentrasi 100\% : tabung 1 diisi $1 \mathrm{ml}$ perasan awal, itu sebagai konsentrasi 100\%, 2) Konsentrasi $75 \%$ : tabung 2 diisi $0,25 \mathrm{ml} \mathrm{Pz}$ steril ditambahkan perasan daun keji belingkonsentrasi $100 \%$ sebanyak 0,75 $\mathrm{ml}$, dihomogenkan, 3) Konsentrasi $50 \%$ : pada tabung 3 diisi $0,50 \mathrm{ml}$ $\mathrm{Pz}$ steril ditambahkan perasan daun keji belingkonsentrasi $100 \%$ sebanyak $0,50 \mathrm{ml}$, dihomogenkan, 4) Konsentrasi $25 \%$ : pada tabung 4 diisi $0,75 \mathrm{ml} \mathrm{Pz}$ steril ditambahkan perasan daun keji belingkonsentrasi 100\% sebanyak 0,25 $\mathrm{ml}$, dihomogenkan, 5) Konsentrasi $10 \%$ : pada tabung 5 diisi $0,90 \mathrm{ml}$ $\mathrm{Pz}$ steril ditambahkan perasan daun keji belingkonsentrasi $100 \%$ sebanyak $0,10 \mathrm{ml}$, dihomogenkan.

\section{Pemeriksaan Sampel}

\section{Hari Pertama:}

Alat dan bahan yang dibutuhkan disiapkan. Lalu api spirtus dinyalakan dengan korek api. Masing-masing tabung diberi label sesuai dengan konsentrasinya, yaitu konsentrasi 100\%, 75\%, 50\%, 25\%, 10\%,0\%. Kemudian ose bulat dipanaskan diatas nyala api spirtus selanjutnya suspense kuman Staphylococcus aureus diambil sebanyak 1 masa ose dan dibiakkan di tabung berlabel $100 \%$ dengan cara ose digesekkan di dinding permukaan media cair sebanyak 5 kali. Kemudian diambil lagi 1 mata ose kuman Staphylococcus aureus pada suspense kuman dan dibiakkan pada tabung berlabel $75 \%$ begitu seterusnya sampai pada tabung kontrol. Semua perlakuan dilakukan secara steril dekat dengan api. Selanjutnya tabung ditutup dengan kapas berlemak dan diinkubasi pada suhu $37^{\circ} \mathrm{C}$ selama 24 jam.

\section{Hari Kedua :}

Masing-masing tabung reaksi diamati apakah terjadi kekeruhan atau tidak. Kemudian diambil masing-masing konsentrasi yang terlihat keruh, dan diuji kembali ke media padat Manitol Salt Agar (MSA) dengan tujuan memastikan apakah kuman tersebut adalah Staphylococcus aureus. Lalu ose bulat dipanaskan diatas nyala api spirtus, diambil 1 mata ose kuman yang ada pada masing-masing konsentrasi tadi. Kemudian ditanam di media padat dengan cara digoreskan pada permukaan media. Kemudian Inkubasi kembali pada suhu $37^{\circ} \mathrm{C}$ selama $24 \mathrm{jam}$.

\section{Hari Ketiga :}

Hasil pertumbuhan diamati pada media padat apakah terbentuk koloni yang mengidentifikasi kuman tersebut adalah Staphylococcus aureus. Lalu dicatat konsentrasi terkecil tadi sebagai daya hambat pertumbuhan kuman. 


\section{Analisis Data}

Data hasil penelitian yang diperoleh dianalisa secara statistik dengan menggunakan analisa varian (ANOVA) dengan tingkat kesalahan $5 \%(0,05)$ dan dilanjutkan dengan uji Tukey's Honest Significant Difference (Tukey's HSD).

\section{HASIL PENELITIAN}

Setelah dilakukan pemeriksaan, maka diperoleh hasil seperti yang tercantum pada Tabel 1 dibawah ini :

Tabel 1. Jumlah koloni Staphylococcus aureus pada Media MSA yang sudah diperlakukan dengan perasan Daun Keji Beling Sericocalyx crispus

\begin{tabular}{|c|c|c|c|c|c|c|}
\hline $\begin{array}{c}\text { Replik } \\
\text { asi }\end{array}$ & $\mathbf{0 \%}$ & $\mathbf{1 0 \%}$ & $\mathbf{2 5 \%}$ & $\mathbf{5 0 \%}$ & $\mathbf{7 5 \%}$ & $\begin{array}{c}\mathbf{1 0 0} \\
\mathbf{\%}\end{array}$ \\
\hline $\mathbf{1}$ & 1270 & 1225 & 988 & 510 & 53 & 20 \\
\hline $\mathbf{2}$ & 1165 & 1167 & 1120 & 660 & 76 & 17 \\
\hline $\mathbf{3}$ & 1390 & 1189 & 890 & 550 & 110 & 23 \\
\hline $\mathbf{4}$ & 1367 & 1196 & 999 & 575 & 90 & 15 \\
\hline $\begin{array}{c}\text { Jumla } \\
\mathbf{h}\end{array}$ & 5192 & 4777 & 3997 & 2295 & 329 & 75 \\
\hline $\begin{array}{c}\text { Rata }- \\
\text { rata }\end{array}$ & 1298 & 1194 & 999 & 574 & 82 & 19 \\
\hline SD & 102. & 23.9 & 94.2 & 63.4 & 23.9 & 3.50 \\
\hline
\end{tabular}

Dari Tabel 1. diatas dapat dilihat ratarata jumlah koloni dari setiap konsentrasi berbeda. Pada konsentrasi 100\%, 75\%, 50\%, $25 \%, 10 \%, 0 \%$ memiliki rata-rata berbeda yang berarti masih terdapat pertumbuhan bakteri Staphylococcus aureus, akan tetapi semakin besar konsentrasi yang diberikan semakin sedikit pula jumlah koloni pertumbuhannya.

\section{PEMBAHASAN}

Dari hasil analisis data yang diperoleh dari uji statistik angka probabilitas 0,001 lebih kecil dari 0,05 maka $\mathrm{H}_{0}$ ditolak, hasil menunjukan bahwa masing-masing perlakuan yang diberikan berupa beberapa konsentrasi perasan daun keji beling memberikan pengaruh terhadap Staphylococcus aureus namun tidak efektif. Menurut Gillespie (2010) menyatakan bahwa zat antibakteri bersifat bakterisidal ditandai dengan tidak adanya pertumbuhan koloni bakteri pada media agar. Banyak faktor yang mempengaruhi pertumbuhan bakteri, namun dalam penelitian ini memiliki faktor pada kondisi fisik yaitu suhu, oksigen, $\mathrm{pH}$, lingkungan.

Mekanisme kerja antibakteri meliputi menghambat dan mengganggu metabolisme sel bakteri, menghambat sintesis dinding sel bakteri, mengganggu permeabilitas membran sel bakteri, menghambat atau merusak sintesis nukleat selbakteri (Jawetz, 2008). Perasan daun keji beling (Sericocalyx crispus Linn) memiliki kandungan zat aktif seperti alkaloid, flavonoid, saponin.

Berdasarkan hasil penelitian yang telah dilakukan maka dapat disimpulkan bahwa daun keji beling bersifat antimikroba, pada konsentrasi 10\%, 25\%, 50\% masih terdapat pertumbuhan kuman namun pada konsentrasi $75 \%$ lebih efektif bias menghambat kuman hal ini karena daun keji 
beling memiliki kandungan senyawa flavonoid, saponindan alkaloid yang mampu menghambat dari konsentrasi terbesar bisa mempengaruhi mekanisme kerja bakteri dan menghambat pertumbuhan bakteri.

\section{KESIMPULAN}

Perasan daun keji beling (Sericocalyx crispus Linn) fektif menghambat pertumbuhan Staphylococcus aureus. Pada konsentrasi $100 \%$ ditemukan pertumbuhan koloni bakteri pada media Manitol Salt Agar (MSA) dengan rata-rata 19 koloni, konsentrasi 75\% didapatkan rata-rata 82 koloni, konsentrasi $50 \%$ didapatkan rata-rata 574 koloni, konsentrasi $25 \%$ didapatkan rata-rata 999 koloni, pada konsentrasi 10\% didapatkan ratarata 1194 koloni dan konsentrasi 0\% (kontrol) didapatkan rata-rata 1298 koloni. Namun yang paling efektif menghambat pada konsentrasi $75 \%$.

\section{DAFTAR PUSTAKA / BIBLIOGRAPHY}

Benigna, Maria. 2015. Uji Daya Hambat Ekstrak Daun Keji Beling (Strobilanthes crispa BI.) Terhadap Pertumbuhan Bakteri Salmonella typhi Secara In Vitro. Skripsi. Universitas Sanata Dharma, Yogyakarta.
Mursito, Bambang. 2005. Ramuan Tradisional Untuk Gangguan Ginjal. Penebar Swadaya, Jakarta.

Jawetz, E., J.L. Melnick., E.A. Adelberg., G.F. Brooks., J.S. Butel., dan L.N. Ornston. 1995. Mikrobiologi Kedokteran. Edisi ke-20 (Alih bahasa : Nugroho \& R.F.Maulany). Jakarta : Penerbit Buku Kedokteran EGC. hal. 211,213,215.

Jawetz, Melnick, Adelberg. 2008. Mikribiologi Kedokteran.(alihbahasa: H. Hartanto, C Rachman, A. Dimanti, A. Diani).Jakarta: EFC.p.199-200:233

Ryan, K.J., J.J. Champoux, S. Falkow, J.J. Plonde, W.L. Drew, F.C. Neidhardt, and C.G. Roy. 1994. Medical Microbiology An Introduction to Infectious Diseases. 3rd ed. Connecticut: Appleton\&Lange. p.254.

Warsa, U.C. 1994. Staphylococcus dalam Buku Ajar Mikrobiologi Kedokteran. Edisi Revisi. Jakarta : Penerbit Binarupa Aksara. hal. 103-110. 